\title{
Problem-based learning versus lectures: Comparison of academic results and time devoted by teachers in a course on Dentistry in Special Patients
}

\author{
Luis A. Moreno-López, Ma Luisa Somacarrera-Pérez, MM Díaz-Rodríguez, Julián Campo-Trapero, Jorge \\ Cano-Sánchez
}

Dpto. Medicina y Cirugía Bucofacial. Universidad Complutense de Madrid

Correspondence:

Dpto. Medicina y Cirugía Bucofacial.

Universidad Complutense de Madrid.

Pza. Ramón y Cajal $s / n$.

28034 Madrid.

medicinaoral@gmail.com

Received: 22/10/2008

Accepted: 08/07/2009

Moreno-López LA, Somacarrera-Pérez ML, Díaz-Rodríguez MM, Campo-Trapero J, Cano-Sánchez J. Problem-based learning versus lectures: Comparison of academic results and time devoted by teachers in a course on Dentistry in Special Patients. Med Oral Patol Oral Cir Bucal. 2009 Nov 1;14 (11):e583-7.

http://www.medicinaoral.com/medoralfree01/v14i11/medoralv14i11p583.pdf

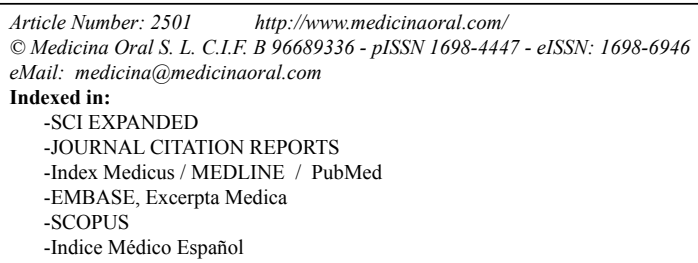

\begin{abstract}
Objectives: Problem-Based Learning (PBL) is a teaching-learning technique centred on the complete development of the student. It has been successfully implemented in several universities, notably in the health sciences. The process of creating the European Higher Education Area, initiated in Bologna, encourages European universities to use new methodologies in the teaching-learning process, including PBL. Our objectives were to analyze the results obtained by using PBL with fifth-year Dentistry students. Study design: Comparison of academic results between students receiving lectures and PBL participants, and assessment of differences between them in the time devoted to tasks by students and teachers. Results: PBL participants obtained higher grades compared to those receiving lectures only $(p<0.05)$. The two student groups devoted the same amount of time to this subject but the time distribution of tasks was very different, with PBL students spending more time on group work and analysis of the literature. The teachers devoted much more time to the PBL group. Conclusions: PBL is a teaching-learning methodology that improves student academic results. PBL diverts student time to more complex tasks but requires a greater commitment from the teachers.
\end{abstract}

Key words: PBL, special care dentistry, European space for higher education.

\section{Introduction}

Problem-Based Learning (PBL) is a learning methodology in which the starting point is a problem or situation that allows the student to identify the requirements for a better understanding of the problem, identifying principles that sustain knowledge and achieving learning objectives related to each element of the curriculum (1). The essential element of PBL is student-centred learn- ing, i.e., emphasising self-directed learning. In PBL, students must take responsibility for their own learning, developing strategies they find effective to achieve their learning objectives (2-4). In the context of learning objectives (institutional and individual), PBL obliges students to develop abilities related to organization, information management and critical analysis of evidence (skills associated with learning to learn). It has been re- 
ported that PBL students have the subjective perception that they acquire superior professional skills (5). When using this methodology, teachers must take into account the existing knowledge base of the students, which can vary in quantity and quality at the beginning of their professional training. Although their previous knowledge can be erroneous and is often disorganised, the heads of our students are not empty bottles into which we pour information.

Many variants of the original PBL proposals have been developed over the past 30 years, although the fundamental elements have remained relatively constant. The essence of this approach is that the problem appears first, with no advanced reading or preparation, serving to stimulate a need for knowledge. From five to eight students collaborate in a group (tutorial) with one or more facilitators (tutors) in order to jointly identify and define different problems, developing hypotheses to explain them and examining existing knowledge on the matter. Students determine and explore what they have already studied and what they must learn in order to develop their understanding of the problem. In other words, a need to learn is created in the students, in this case to solve a problem. The key elements of PBL are the formulation of questions that can be explored and the response to these questions by means of a systematic search, self-directed questions, and the review and testing of hypotheses by the application of newly acquired knowledge (6).

There is evidence that active participation in learning is more satisfactory than the passive transfer of information from teacher to student. This has been demonstrated in research in Dentistry schools $(7,8)$, which also showed that active learning facilitates retention and recall (9). PBL emphasizes active learning centred on students, who are challenged to examine, question, reflect, seek meanings and understand the basic science of a discipline, developing approaches to the solution of problems in the specific context of their future professional setting (2). Discussing clinical or other problems in small groups promotes the connection of ideas and concepts (10) and encourages cooperation instead of competition among students (11).

One negative aspect of PBL is the higher cost for the institutions, and it has been questioned whether students have an adequate background in basic science, although reports have been contradictory (12).

Our main objective was to compare academic results between two student groups: one engaged in PBL and the other in traditional learning with lectures. The secondary objective was to compare the time devoted by the students and teachers between each study group.

\section{Material and Methods}

The study was carried out in students and teachers of the 2006/7 course on "Special Care in Dentistry" for 5th-yr students at the Universidad Europea of Madrid (UEM). Participating teachers and students gave their written consent to participation in the study, which was approved by the research committee of the Health Sciences School of our university. One credit is awarded for this subject, which is taught in 10 hours of theoretical classes ( $1 \mathrm{hr}$ per week for 10 weeks) by three teachers, who gave the lectures and conducted the tutorials for the students in this study. The subject was taught from October to December. A PBL group was proposed, with the tutor as the expert.

Fifty-one students agreed to participate. They were randomly distributed between two age- and sex-matched groups: a study group $(\mathrm{n}=15)$ and a control group $(n=36)$. We tested the similarity of the groups in terms of their previous academic performance by comparing their marks in 4th-yr Medical Pathology; the mean mark was $6.9 / 10$ for the study group and 7.1/10 for the control group. Sample size was not calculated because the possible differences could not be previously estimated. The study group was limited to 15 people because of the expected time commitment of the teachers.

The proposed work methodology for the course was explained to each student group. Control group students were informed about the number of classes during the year and how they would develop. Study group students were informed about PLB, assigned to work subgroups and given the problem/case to be worked on. Both groups were told that an examination had to be taken to pass the subject and that it would consist of solving three clinical cases (similar to those on which the study group would work). In control group lectures, the teacher described and solved several cases similar to those that would appear in the examination. Hence, we obtained an instrument to evaluate and compare the two groups.

The study group was distributed among three subgroups of five students each. Each subgroup was given a problem. The problem consisted of a clinical case that described a usual situation in clinical practice. As a final result, the teacher expected the students to have at least met the following objectives:

- To assess the situation of the patient based on the available data

- To present a series of measures to be taken in the case of the need for dental treatment according to the type of treatment required

Finally, they had to communicate their conclusions to the other members of the study group with an on-screen presentation and give the rest of the group the documentation they had consulted.

Each sub-group was assigned a tutor, with whom they had to have at least two tutorials before the presentation. Finally, and in common with the other subgroups, they 
had to take examination in order to pass the subject. For the study group, the examination mark represented $50 \%$ of the final mark for the subject; the other $50 \%$ was awarded for problem-solving work and presentation to the rest of the group. Each subgroup kept a work diary that they had to present to evaluate the resolution of the problem. This diary had to report on the tasks conducted by each student, the time devoted by each person to each task and the problems that arose in developing the different tasks.

The control group received lectures in which the teacher made a presentation and then described the solution to similar clinical cases to those addressed by the study group. They had to study the material presented in class and take the same examination as the study group in order to pass the subject. Each student received a questionnaire on the time devoted to each task.

In the examination, all students had to present the pretreatment evaluation of three clinical cases that were similar to those solved during learning by students in the study group or solved by the teacher in the control group.

Finally, data were gathered on the time devoted by each individual in each group, and their exam marks were obtained.

The following variables were studied in order to meet the study objectives:

Student exam mark for the subject

Time devoted to tutorials with teachers

Time devoted to tasks outside the classroom

Time devoted to study

Time devoted to gathering information outside the classroom

Time devoted to discussion among students outside the classroom

Time devoted by teachers in each group

The Student's t test for independent samples (SPSS package) was used to analyse differences in means between control and study groups.

\section{Results}

\section{- Student examination marks}

The distribution of examination marks between the groups is shown in Table 1. The mean mark was higher $(p<0.05)$ in the study group than in the control group.

Table 1. Distribution of examination marks between the groups.

\begin{tabular}{|l|c|c|c|}
\hline GROUP & $\mathrm{N}$ & Mean (SD) & $\mathrm{p}$ \\
\hline CONTROL & 36 & $6.9(1.3)$ & \\
\hline STUDY & 15 & $7.6(0.9)$ & 0.041 \\
\hline
\end{tabular}

\section{- Time devoted by students}

Table 2 depicts the distribution of the remaining study variables between the groups. The PBL group (study group) devoted fewer hours to study (13.13 h vs. $26.03 \mathrm{~h}$ ) but spent more hours on information retrieval, tutorials and discussion with classmates. The total time devoted to all tasks was $41.39 \mathrm{~h}$ in the control group (26 devoted to "study", $62.8 \%$ of total) and $35.46 \mathrm{~h}$ in the PBL group (13 to "study", $36.7 \%$ of total). These differences in times were all statistically significant.

- Time employed by teachers

Table 2 shows the mean result for each of the three participating teachers. Despite the small sample size, it could be observed that much more teacher time was devoted to the study group. Moreover, since the study group was formed by 15 students and the control group by 36 , the teacher-hours: student ratio was 1.35 in the PBL group and 0.2 in the control group; this difference was not statistically significant, probably due to the small sample size.

Tabla 2. Time devoted by students and teachers in different tasks. In hours.

\begin{tabular}{|c|c|c|c|c|}
\hline & GROUP & $\mathbf{N}$ & $\begin{array}{c}\text { Mean } \\
\text { (SD) }\end{array}$ & $p$ \\
\hline \multicolumn{5}{|c|}{ STUDENTS } \\
\hline \multirow[t]{2}{*}{ STUDY } & CONTROL & 36 & $\begin{array}{l}26.03 \\
(18.7)\end{array}$ & \\
\hline & STUDY & 15 & $\begin{array}{l}13.13 \\
(4.9)\end{array}$ & $p<0.05$ \\
\hline \multirow[t]{2}{*}{ INFORMATION } & CONTROL & 36 & $\begin{array}{l}2.61 \\
(3.3) \\
\end{array}$ & \\
\hline & STUDY & 15 & $\begin{array}{l}5.53 \\
(2.7)\end{array}$ & $p<0.05$ \\
\hline \multirow[t]{2}{*}{ TUTOR } & CONTROL & 36 & $\begin{array}{l}0.06 \\
(0.2)\end{array}$ & \\
\hline & STUDY & 15 & $\begin{array}{l}2.60 \\
(1.4)\end{array}$ & $p<0.01$ \\
\hline \multirow[t]{2}{*}{ DISCUSSION } & CONTROL & 36 & $\begin{array}{l}2.47 \\
(1.6)\end{array}$ & \\
\hline & STUDY & 15 & $\begin{array}{l}5.20 \\
(3.1) \\
\end{array}$ & $p<0.01$ \\
\hline \multicolumn{5}{|c|}{ TEACHERS } \\
\hline \multirow[t]{2}{*}{ CLASSES } & CONTROL & 3 & 3.3 & \\
\hline & STUDY & 3 & 3.3 & NSD \\
\hline \multirow[t]{2}{*}{ STUDY } & CONTROL & 3 & 3 & \\
\hline & STUDY & 3 & 4 & NSD \\
\hline \multirow[t]{2}{*}{ TUTORSHIP } & CONTROL & 3 & 1 & \\
\hline & STUDY & 3 & 13 & NSD \\
\hline \multirow[t]{2}{*}{ H/STUDENT } & CONTROL & 3 & 0.2 & \\
\hline & STUDY & 3 & 1.35 & NSD \\
\hline
\end{tabular}

NDS: No Significant Difference 


\section{Discussion}

We have found no studies that quantitatively assessed differences in learning between lectures and PBL developed in parallel. One comparative study showed slightly superior academic results in a PBL group than in a group receiving lectures, but the difference did not reach significance (13).

In the present study, PBL proved to be a useful tool for students learning Special Care in Dentistry. The PBL students obtained a good mean mark (7.6/10) in the examination, which was higher than the mean mark achieved by those receiving conventional lectures. The contact time between teacher and student was much higher in the PBL students, which not only improves the teaching-learning process but is also reported (14) to communicate good practice guidelines more effectively (not addressed in the present investigation).

This study has some limitations. In "classic" PBL, the tutor should not be an expert on the subject, which was precluded by the need to comply with the academic regulations of our centre. Moreover, although the groups worked independently, it was not possible to prevent communication and transfer of knowledge between the groups. Although this is not in itself negative, it might have interfered with the final exam result. In addition, the fact that the PBL students had no previous experience of this methodology might have increased their work times.

PBL allowed these students to devote less time overall to the subject, although this difference was not significant. They spent a significantly lower proportion of this time (vs. controls) on "study" and a significantly higher proportion on more complex tasks with motivating power, such as information searches outside the classroom and discussions of this information with their colleagues.

This work methodology requires a greater use of new technologies that are not yet widely available to the general and university population in Spain. According to a study by the Universidad of Sevilla, only $29.4 \%$ of students habitually used Internet for learning tasks (15).

One of the objectives of PBL is to prepare students for continuous training throughout their professional career. PBL permits students to develop abilities to analyse problems autonomously. They develop efficient team work, accepting different roles and communicating with their peers (16). Introduction of PBL into the curriculum requires a an implementation plan both for students and for teachers, not only with regard to the training programme, as assumed by most of the institutions that have developed it (17), but also with respect to the distribution of human resources within the university.

The quality of education and research in university faculties is changing, requiring economic resources to support its development. It is important that economic considerations do not wed us to a teacher-centred educational approach that is only apparently efficient in terms of time and is not sustained by any educational theory (12).

PBL is a method that can sometimes be difficult to implement because it requires considerable time, costs and more personnel (18). The present study found that much more teaching time was required for PBL students and that the distribution of their time among types of task greatly differed, indicating the need for a reorganisation of human and material resources by university institutions. According to our findings, this reorganisation would result in an improved academic performance by the student.

\section{Conclusions}

Students who participated in PBL obtained significantly higher grades than those attending lectures during the course. The time employed by the two student groups was similar, but the distribution among tasks was very different. PBL students dedicate more time to group work and reference analysis than those attending conventional lectures. The time devoted by teachers was much higher in the PBL group. PBL is a teaching-learning methodology that improves the academic results of students. In PBL, a larger proportion of student time is devoted to more complex tasks and a greater commitment of teaching staff time is required.

\section{References}

1. Branda LA. Implementing problem based learning. J Dent Educ. 1990;54:548-9.

2. Neufeld VR, Barrows HS. The "McMaster Philosophy": an approach to medical education. J Med Educ. 1974;49:1040-50.

3. Schmidt HG. Foundations of problem-based learning: some explanatory notes. Med Educ. 1993;27:422-32.

4. Colliver JA, Verhulst SJ, Barrows HS. Self-assessment in medical practice: a further concern about the conventional research paradigm. Teach Learn Med. 2005;17:200-1.

5. Pau AK, Croucher R. The use of PBL to facilitate the development of professional attributes in second year dental students. Eur J Dent Educ. 2003;7:123-9.

6. Mennin S, Majoor G. Problem Based Learning. Position Paper. http://www.the-networktufh.org/publications_resources/positioncontent.asp? $\mathrm{id}=6 \& \mathrm{t}=$ Position+Papers. Access dic. 1st, 2008.

7. Haghparast N, Sedghizadeh PP, Shuler CF, Ferati D, Christersson C. Evaluation of student and faculty perceptions of the PBL curriculum at two dental schools from a student perspective: a crosssectional survey. Eur J Dent Educ. 2007;11:14-22.

8. Fincham AG, Shuler CF. The changing face of dental education: the impact of PBL. J Dent Educ. 2001;65:406-21.

9. Bransford JD, Brown AL, Cocking RR (Eds.) How People Learn: Brain Mind, Experience, and School. National Academy of Sciences. National Academy Press, Washington, D.C. 2000.

10. Wang G, Tai B, Huang C, Bian Z, Shang Z, Wang Q, et al. Establishing a multidisciplinary PBL curriculum in the School of Stomatology at Wuhan University. J Dent Educ. 2008;72:610-5.

11. Schmidt HG, Moust JHC. Factors affecting small-group tutorial learning: A review of research. In: Evensen DH \& Hmelo CE (Eds): Problem-Based Learning: A Research Perspective on Learning Interactions. Mahwah, NJ: Lawrence Erlbaum; 2000. p. 19-52.

12. Winning T, Townsend G. Problem-based learning in dental edu- 
cation: what's the evidence for and against...and is it worth the effort?. Aust Dent J. 2007;52:2-9.

13. Rich SK, Keim RG, Shuler CF. Problem-based learning versus a traditional educational methodology: a comparison of preclinical and clinical periodontics performance. J Dent Educ. 2005;69:649-62.

14. Martín García P, Ríos Santos JV, Segura Egea JJ, Fernández Palacín A, Bullón Fernández P. Dental audit (I): Exact criteria of dental records; results of a Phase-III study. Med Oral Patol Oral Cir Bucal. 2008;13:E407-13.

15. Castelló Castañeda C, Ríos Santos JV, Bullón P. Analysis of the knowledge and opinions of students and qualified dentists regarding the use of computers. Med Oral Patol Oral Cir Bucal. 2008;13:E71-6.

16. Plasschaert AJ, Manogue M, Lindh C, McLoughlin J, Murtomaa $\mathrm{H}$, Nattestad A, et al. Curriculum content, structure and ECTS for European dental schools. Part II: methods of learning and teaching, assessment procedures and performance criteria. Eur J Dent Educ. 2007;11:125-36.

17. Farmer EA. Faculty development for problem-based learning. Eur J Dent Educ. 2004;8:59-66.

18. Katsuragi H. Adding problem-based learning tutorials to a traditional lecture-based curriculum: a pilot study in a dental school. Odontology. 2005;93:80-5.

This project received an OTRI grant from the UEM in its 2005/2006 call. 